\title{
Platinum Group Element (PGE) geochemistry as a tool to determine sulfide saturation and magma fertility
}

\author{
M. MiSZTELA ${ }^{1}$, I. CAMPBELL $^{1}$ \\ ${ }^{1}$ Research School of Earth Sciences, Australian National \\ University, 2601 Acton, ACT, Australia \\ (monika.misztela@anu.edu)
}

Porphyry systems are considered as the primary source of the world`s $\mathrm{Cu}, \mathrm{Au}$ and Mo [1]. However, not all porphyries are associated with economic deposit, even though they share similar properties to ore-bearing systems. We hypothesize that the timing of sulfide saturation relative to volatile saturation plays a crucial role in controlling the prospectivity of a porphyry.

We use PGE geochemistry to track the timing of the sulfide saturation in magmatic systems. PGE are used in preference to $\mathrm{Au}$ or $\mathrm{Cu}$ because they are more sensitive indicators of magmatic processes, and their solubility in hydrothermal fluids is low. Their concentrations in wholerock reflect magmatic, rather than hydrothermal processes [2].

Modelling using Petrolog3 software and the Rayleigh fractionation equation to calculate incompatible elements variations shows that the ore-bearing Yerington Batholith underwent c.a $70 \%$ fractionation prior to sulfide saturation (Fig. 1 b) whereas the barren Mount Hagen suite underwent only c.a $10 \%$ fractionation (Fig. 1 a). Fractionation produced an enrichment of over $\mathrm{x} 3$ in incompatible $\mathrm{Cu}$ and $\mathrm{Au}$ in the Yerington suite whereas in the Mt. Hagen suite enrichment is only c.a 1 . Furthermore, once the magma becomes sulfide saturated, $\mathrm{Cu}$ and $\mathrm{Au}$ are sequestered by the sulfide phase and not available to enter the ore fluid. Late sulfide saturation and the prolonged enrichment in $\mathrm{Cu}$ and $\mathrm{Au}$, prior to sulfide saturation, make Yerington a favourable suite for ore forming.

a)

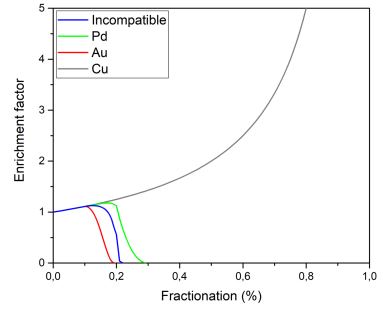

b)

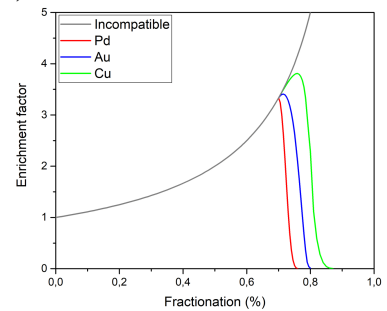

Figure 1: Modelling of $\mathrm{Pd}, \mathrm{Au}$ and $\mathrm{Cu}$ in silicate melts.

[1] Cooke (2013) SEG, 7. [2] Mungal 1\& Brenan (2014)

Geochimica et Cosmochimica Acta, 125, 265-289. 